\title{
Algorithm's Design in MATLAB using a RTL Device as a Spectrum Meter of the UHF Band, to evaluate the Temporary and Space Availability of Individual and Joint Television Channels within the Aerotechnical Building of The Simon Bolivar Air Base in Guayaquil City
}

\author{
Wilson G. Salgado, Mario M. Toledo, Miguel Molina, Washington Medina, Javier I. Hidalgo
}

\begin{abstract}
The great congestion of services in the unlicensed bands existing in homes and jobs, due to the large number of users, is reflected in interference, latency and packet loss; causing problems in the quality of service (QoS, for its acronym in English), this crisis in wireless communications has led to research in technologies with opportunistic access, for this is necessary to know the temporal and spatial spectral availability to estimate the frequencies that can be used with other technologies based on OSA.

Keywords-BW, FCC, GANT, OSA, UHF, LC, LCC, IoT, NGW, PN, Lambda, QoS, CR, ARCOTEL, TVWS.
\end{abstract}

\section{INTRODUCTION}

Throughout the years, the theory of dynamic spectrum access (DAS), gave rise to the methodology and philosophy of opportunistic spectrum access (OSA), allowing to estimate the amount of blank spaces in the use of television radio spectrum (RF) in heterogeneous wireless environments. This is a result of the number of wireless devices and technologies that have grown to the point where there are more devices than people in the world [1].

This combines a demand and an excessive use of the radio electric spectrum, currently assigned in a static manner, which causes a shortage of frequencies to develop in the coming years.

Digital Object Identifier (DOI): http://dx.doi.org/10.18687/LACCEI2018.1.1.202 ISBN: 978-0-9993443-1-6

ISSN: $2414-6390$

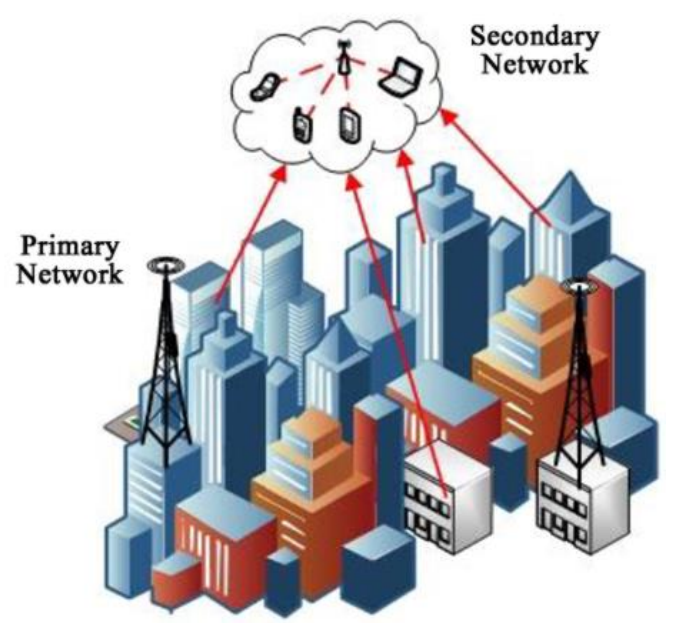

Fig. 1: Urban stage with a high density of buildings [1].

This paper analyzes the availability of UHF television frequency, in the temporal and spatial aspects of a building in a densely populated urban area as seen in Figure 1, by measuring signal intensity and power density; In order to establish differentiations and conclusions, to reuse these radio frequencies in other services, building a way to the Internet of Things (IoT) and Converging Networks (NGN).

The great congestion of services in the unlicensed bands existing in homes and jobs, due to the large number of users, is reflected in interference, latency and packet loss; causing problems in the quality of service (QoS, for its acronym in English), this crisis in wireless communications has led to research into technologies with opportunistic access, in which the teams are smart enough to take advantage of their hardware to visualize their environment and discover which frequencies are available so as not to cause interference problems with other users. For this it is necessary to know the spectral availability: temporal and spatial to estimate the frequencies that can be used with other technologies based on OSA. 
Algorithms will be used to establish relationships of linearity, correlation, power, signal strength, unit channels and sets; between the floors of the building; establishing future predictions of the communication devices that can use this spectrum currently with opportunistic access to the spectrum.

This will allow a change of frequency based on a history, considering as a reference the Cognitive Radio that uses the IEEE standard 802.22 [2]. In this summary, frequency availability could be evaluated for the analysis building. It was also possible to determine the temporal availability by channel of a few seconds and several hours.

\section{STATE OF THE ART}

Due to studies [23][4][5] on the distribution of the radio spectrum of various countries, it has been found that their availability between the channels of the licensed bands and those of the free bands differs too much. This availability around the whole spectrum can be seen that it is not efficient because it does not adapt to the arrival of new trends and technological advances.

For this reason, in the ISM bands it is not possible to satisfy the demand for the use of spectrum, due to the existence of a large number of users. Knowing the state of the art made it possible to pose the problem that telecommunications currently have and that require dynamic spectrum access (DSA), opportunistic spectrum access (OSA), among other theoretical bases that are described in current research in wireless communications. Emphasis was placed on evaluating the unit and joint television channels that are temporarily and spatially available for a particular building in a densely populated area in indoor environments, of the UHF-TV band, to suggest its use for particular location of equipment with technologies based on OSA.

One aspect that has not changed over a long period of time is the allocation and distribution of the radioelectric spectrum. These groupings are elaborated by government entities whose main objective is to distribute the frequency bands according to the technological needs of each system.

Users are part and use more and more the new technologies of the market. A generation of large amounts of interference levels between devices is a consequence of this overwhelming number of users that collapse these free bands affecting mainly their coverage and quality of service (QoS).

These channels of the licensed bands that are not in use in certain time intervals are known as White Spaces (WS) [3]. These WS, as can be seen in Figure 2, are distributed throughout the entire radio spectrum, including the television band (TV) that is our frequency band of analysis for the research.

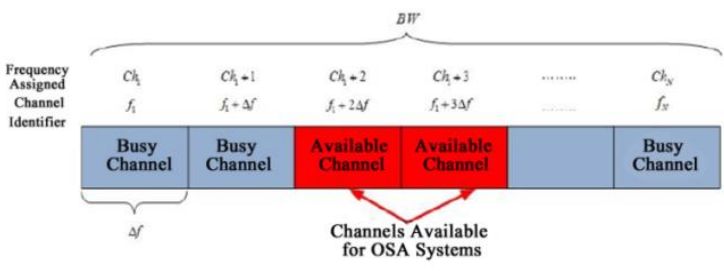

Fig. 2: Spectrum Sensing and Analysis Process [3].

Over time, studies have been conducted to approve that there are portions of spectrum in the TV band whose channels are free most of the time.

Due to the large number of white spaces (WS) in most of the licensed bands of the radio spectrum, it is necessary to take action to take advantage of those channels that are temporarily unoccupied. As a solution, the idea of being able to change the model of use and access to the spectrum appears, from one that is of fixed assignment to one that is assigned dynamically, in order to release some of the collapse suffered by free ISM bands.

\section{DYNAMIC SPECTRUM ACCESS SySTEMS (DSA)}

In Ecuador, the radio spectrum is known to be a renewable natural element, but limited. In addition, as mentioned above, it is administered by regulatory bodies that are the cause of spectrum inefficiency, due to the operation of its rigid and inflexible policies. This regime, used for spectrum allocation, has become completely inadequate since it does not satisfy the current technological needs required by society. The scarcity of the necessary spectrum required by these modern technological services for their operation causes noncompliance with the requirement of wireless services requested by mobile users [22][27].

Due to the call proposed by the FCC to improve radio spectrum management, the first IEEE Symposium on New Frontiers in Networks with Dynamic Spectrum Access (DySPAN) was developed, where the scientific community exhibited various ideas to find a solution to this problem of spectrum management. Within the DySPAN, new tactics were proposed, which can be divided into three models. Therefore, Dynamic Spectrum Access can be categorized into:

1) Exclusive Dynamic Model

2) Open Shared Model (Common Spectrum Model)

3) Hierarchical Access Model

In Figure 3, the categorization of Dynamic Spectrum Access can be observed in a more detailed and comprehensive manner.

$16^{\text {th }}$ LACCEI International Multi-Conference for Engineering, Education, and Technology: "Innovation in Education and Inclusion", 19-21 July 2018, Lima, Peru. 


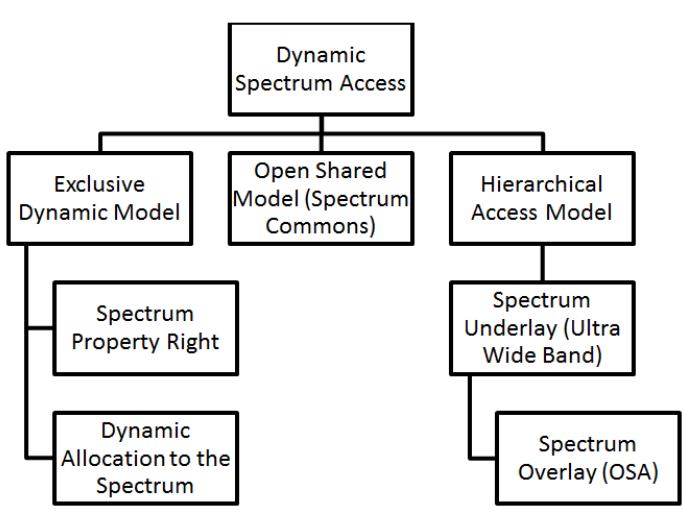

Fig. 3: Categorization of Dynamic Spectrum Access [28].

Opportunistic spectrum access (OSA) is a model that is mainly based on the Spectrum Overlay approach. OSA is a spectrum management model based on the principle that in the analysis band, users as many as primary as secondary can operate and coexist, as long as the secondary users do not interfere in excess to the primary users.

The basic modules of this concept are the opportunity to identify spectrum, the use of it and the regulate policy. The spectrum identification module is in charge of recognizing exactly the white spaces and the free frequency bands that are in the analysis band. The exploitation module is responsible for the processing of data delivered by the first module, in order to decide how the transmission should be executed.

Finally, the regulatory policy is aimed at establishing the base parameters, in order to ensure compatibility with other systems. This process has the purpose of always favoring the secondary users without interfering with the primary users [28].

\section{Metodology}

Given the conditions of the scenario requested for study, a location was chosen with the presence of several buildings in its surroundings and the airport. The building consists of 5 floors of which measurements were made on the roof, on the middle floor and on the ground floor; in order to determine the spectral availability in the scenario, see Figure 5. The measurements were for a period of one week for all of them, the roof, the middle floor and the ground floor. The location is in the north of Guayaquil (Latitude $2^{\circ} 10^{\prime} 4.71$ "S and Longitude $\left.79^{\circ} 52^{\prime} 49.28^{\prime \prime} \mathrm{W}\right)$, see Figure 4 [5].

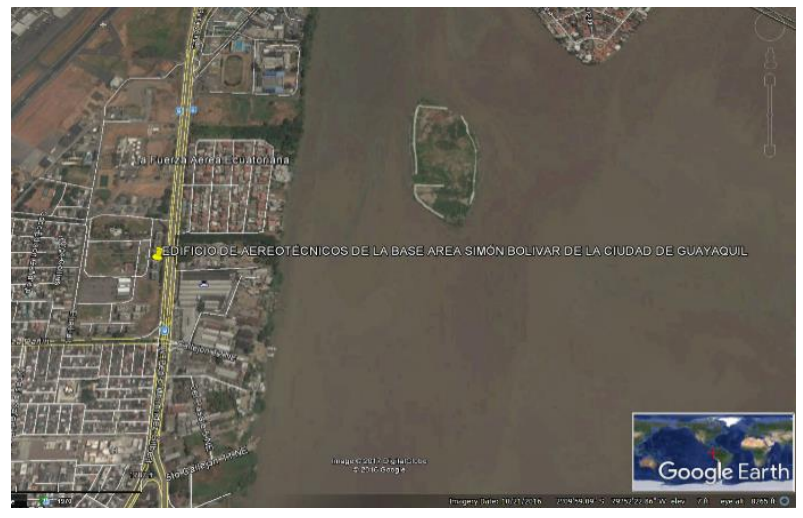

Fig. 4: Geographical Location of the Scenario [5].

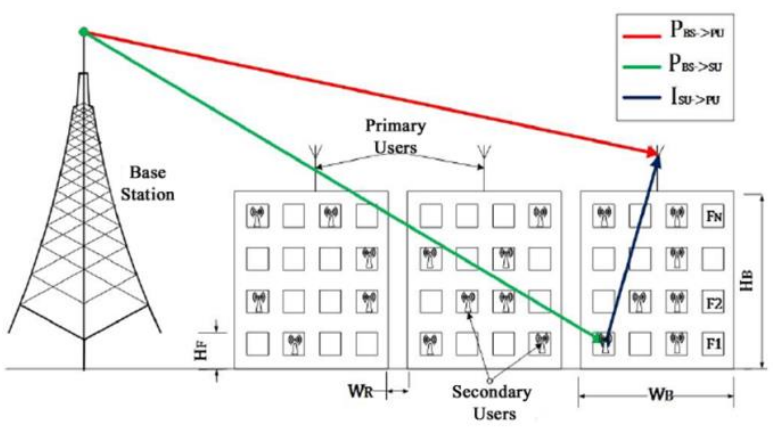

Fig. 5: Side View of the Study Scenario [2].

In order to be able to comply with the proposal, the analysis focused on the UHF-TV band of Ecuador, which ranges from $512 \mathrm{Mhz}$ to $698 \mathrm{Mhz}$ (i.e channels 21 to 51). Each channel has a $6 \mathrm{Mhz}$ bandwidth, the following configuration parameters were used, see Figure 6 [6].

\begin{tabular}{|c|c|}
\hline Parameter & Value \\
\hline Total bandwidth, $B W$ & $512-698 \mathrm{MHz}$ \\
\hline Channel mask, $\Delta f$ & $6 \mathrm{MHz}$ \\
\hline Initial frequency, $f_{o}$ & $512 \mathrm{MHz}$ \\
\hline Final frequency, $f_{N}$ & $698 \mathrm{MHz}$ \\
\hline Initial channel, $C h_{1}$ & 21 \\
\hline Final channel, $C h_{N}$ & 51 \\
\hline Number of channels, $N$ & 31 \\
\hline Number of samples for availability, $N_{S}$ & 25 \\
\hline Threshold power, $\lambda$ & $-75 \mathrm{dBm}$ \\
\hline Sampling time per channel, $T_{C h}$ & $7.2 \mathrm{~s}$ \\
\hline Sampling time, $T_{S}$ & $0.24 \mathrm{~s}$ \\
\hline
\end{tabular}

Fig. 6: Configuration Parameters [6].

Knowing the theory of Dynamic Spectrum Access (DSA) that led to the creation of Opportunistic Spectrum Access (OSA), a method based on an algorithm of data acquisition and creation of matrix in Matlab will be created.

Initially, software is used to visualize UHF TV channels, both analogue and digital in the Frequency Domain, identifying the audio and video carriers for the analog case, and multiple carriers for the digital case.

$16^{\text {th }}$ LACCEI International Multi-Conference for Engineering, Education, and Technology: "Innovation in Education and Inclusion”, 19-21 July 2018, Lima, Peru. 
It will be important to take many samples and then obtain an average with a reference level for the case of digital channels, and identify the video carrier by looking at the tables of the national frequency plan, locating ourselves to take the samples of interest, with another level of reference, and thus obtain the values of power density in decibels for further analysis.

What will be obtained next is a table showing the channels and the times of each day sampled during one week per floor, beginning at a specific time $\mathrm{t} 0$, sweeping all the channels locating the Power Density values in $\mathrm{dB}$ in the table. We will focus on the weekly results for their historical value, considering that the Reference Level (Threshold) will be based on a Sensitivity Analysis given by the level of sensitivity of the receiver that is used in the television system; that is, if I am working with digital channels, a Threshold equal to the digital channel reception sensitivity will be established, and analog channel receiver sensitivity will be used for analog channels.

All this analysis is repeated for each day, 7 days a week for each floor of the building until we complete the three floors. Next we will form a Binary Matrix of channel occupation where it will be assigned with binary numbers when it is free and when it is busy.

If the channel has a lower power than the reference level, we will say that it is a free channel, and if the power is greater than the reference level, we will say that it is a busy channel, see Figure 7. The assignment will be 1 for unoccupied channels and of 0 for occupied channels [4]. With this we can make daily conclusions, and if we put below the matrix, then weekly conclusions. After this analysis, using algorithms we can indicate the probability that a channel is free or occupied per day.

$$
\begin{aligned}
& P_{B S \rightarrow P U} \leq \lambda \\
& P_{B S \rightarrow S U} \leq \lambda \\
& I_{S U \rightarrow P U} \leq \lambda
\end{aligned}
$$

Fig. 7: Determination of channel availability [4].

Once we understand the usage behavior of the spectrum, the most variable channel, the moderately variable and the one that is never variable, will be taken for the conclusions, and based on these three we will obtain the percentages of spectrum use per channel and of all the channels of the television band.

With these conclusions it will be possible to say if it is desired to opportunistically distribute different technologies knowing the bandwidth of the same ones, by means of the use of joint television channels that can cover the requirements so that those frequencies that are underutilized depending on the temporal aspects and space, become efficiently used.

Finally, with the joint channels the probability of temporary unemployment will be determined, in order to use other technologies based on OSA in those available frequencies, for in later studies to estimate without the need to make measurements in a particular building and at a specific time, if it is feasible that the spectrum be reused.

\section{TEMPORARY ANALYSIS OF RESULTS}

The Analysis of the Results is divided by a measurement stage and an analysis of results. In the measurement stage, multiple captures are made by using 38272 measurement points in $\mathrm{dBm}$ or Watts of the radio spectrum in the UHF-TV band, to later convert them to $\mathrm{dB}$ for simplicity of observing the power density in Matlab using algorithms. All this process was done for a period of 3 weeks. The data was captured in 3 points: roof, middle floor and ground floor in order to identify the worst cases. Now we proceed to present the results that were obtained from the channels for the UHF-TV analysis band $(1 \mathrm{Ch}=21-\mathrm{Ch} \mathrm{n}=51)$.

You can see the power levels of the low, middle floor and roof respectively. The great variation of power levels received can be evidenced due to the interferences produced by several factors, among them the losses of propagation by the atmosphere, radome, and signal-to-noise ratio.

In the case of the upper floor, it can be observed in general that the channels have a red tone; this allows us to infer that there is not much availability in that area.

In Figure 8 [6] it is observed that during the process of the measurement weeks, certain channels such as $519 \mathrm{Mhz}$ have extremely low levels ( $\operatorname{Pr}$ ant $<=47 \mathrm{dBm}$ ) and there is not much variability of them, which allows to conclude that they are available for its reuse with Opportunistic Spectrum Access (OSA) systems.

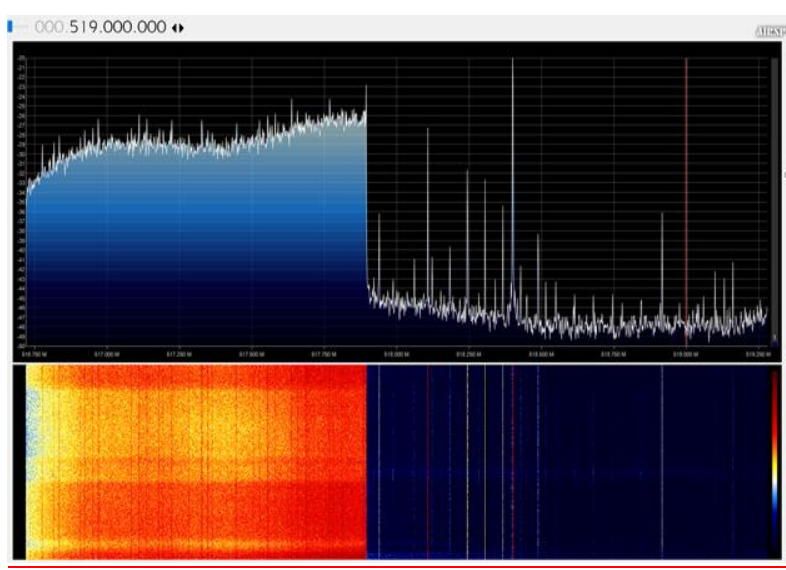

Fig. 8: Levels of Power in the UHF-TV band (Upper Floor) [6].

In the same way, channel 2 (512 - 518 Mhz) has apparently high levels during the week ( $\operatorname{Pr}$ ant $-28 \mathrm{dBm})$. Comparing this level with the threshold (lambda $=-75 \mathrm{dBm}$ ), we can see that almost all of the time these channels are not free to use them, as we can see in Figure 9 [7].

16 $^{\text {th }}$ LACCEI International Multi-Conference for Engineering, Education, and Technology: "Innovation in Education and Inclusion", 19-21 July 2018, Lima, Peru. 


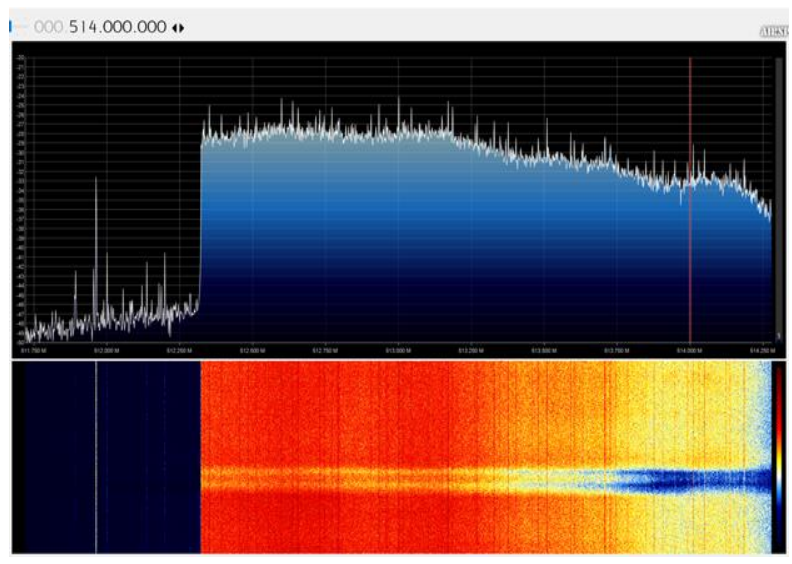

Fig. 9: Levels of Power in the UHF-TV band (Middle Floor) [7].

Additionally there is presence of channels with average power (Pr prom aprox $-25 \mathrm{dBm}$ ) but with great randomness due to thermal noise, like channel 490.416 Mhz found from Woki Toki, which produces intermittence in the received signal, from this we can conclude that the channels have spectral availability for certain time intervals, while other intervals do not.

As we can observe in the same way in Figure 10 [8], taking the channel $93.7 \mathrm{Mhz}$ as an example, it can be seen that the power level increases during certain periods of time of the day (Pr ant approx - $55 \mathrm{dBm}$ ), where this it is translated into the yellow segments that can be seen in the fringes of the channel, otherwise you can also see stripes of light blue or blue color that indicate that the power level is below the threshold, which means that these channels are totally free to reuse them with systems with OSA technology.

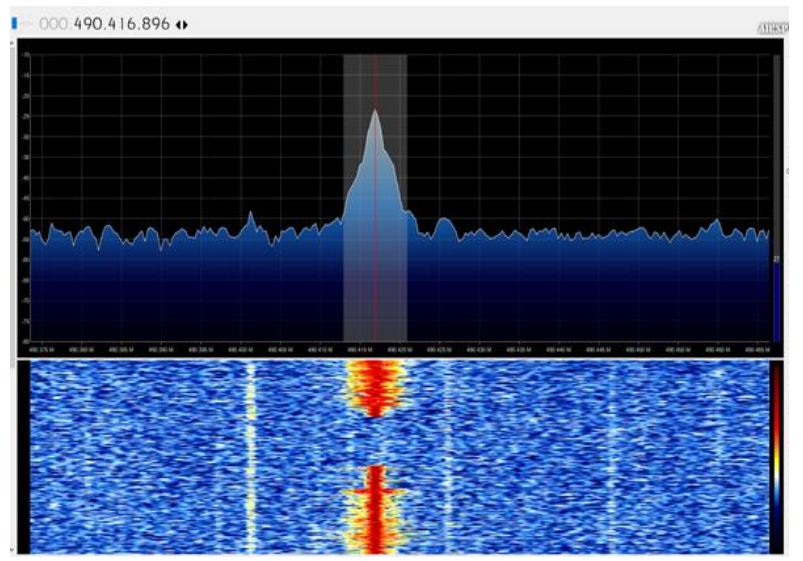

Fig. 10: Levels of Power in the UHF-TV band (Ground Floor) [8].

For the three floors, with thresholds of $+4 \mathrm{~dB}+$ noise floor and $+10 \mathrm{~dB}+$ noise floor, where the Noise Floor was obtained by averaging the free channels on a daily basis, the following probability mass functions of the channels availability were obtained from the Matrix of Joint Channels, as we can see in Figures 11 [9] and 12 [10].

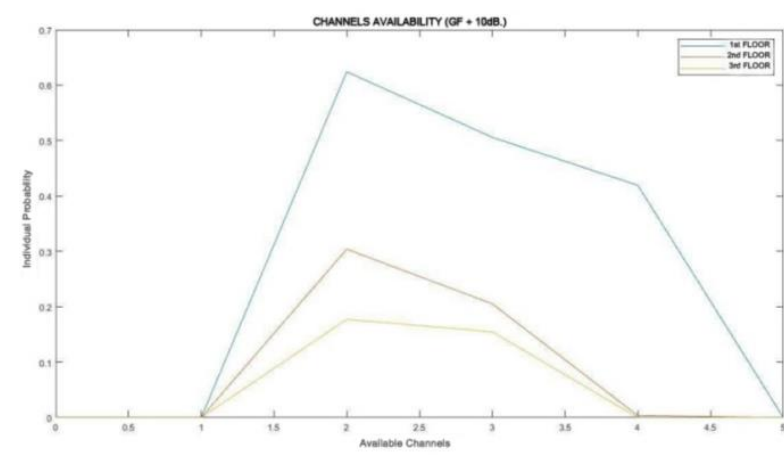

Fig. 11: Probability Mass Function of Channel Availability for Floors 1, 2, 3 with Threshold of $+10 \mathrm{~dB}+$ noise floor [9].

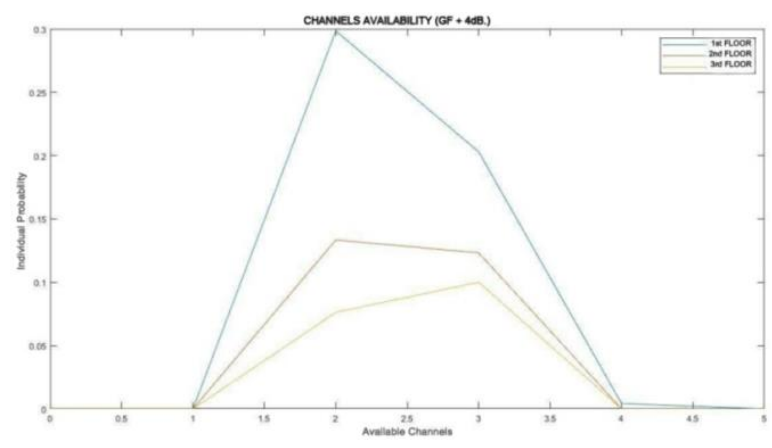

Fig. 12: Probability Mass Function of Channel Availability for Floors 1, 2, 3 with Threshold of $+4 \mathrm{~dB}+$ noise floor [10].

Likewise, the level of available channels for their respective joint probability was determined for all the floors, considering the same thresholds, this can be visualized in Figures 13 and 14 [5] [11].

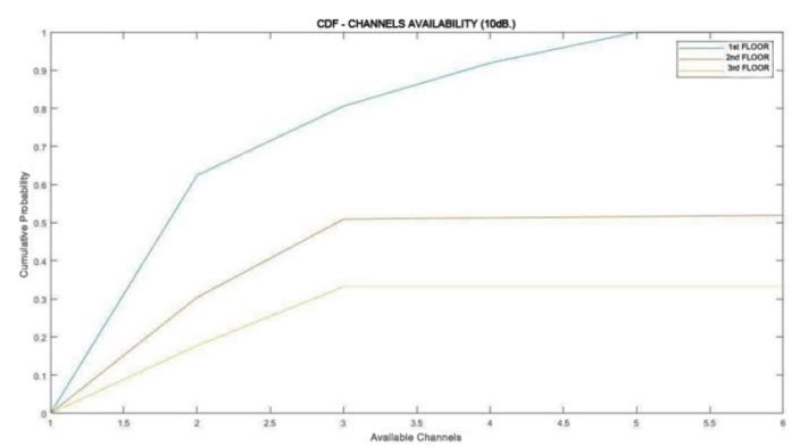

Fig. 13: Probability Recurrence Cumulative Distribution Function of Channel Availability for Floors 1, 2, 3 with Threshold of $+10 \mathrm{~dB}+$ noise floor [5].

$16^{\text {th }}$ LACCEI International Multi-Conference for Engineering, Education, and Technology: "Innovation in Education and Inclusion", 19-21 July 2018, Lima, Peru. 


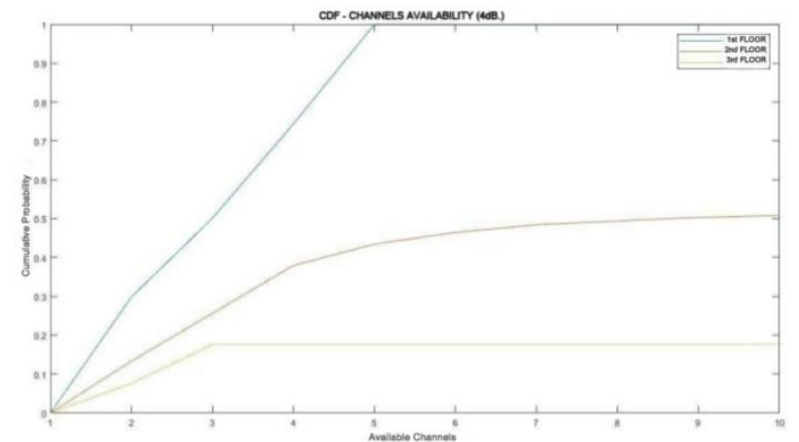

Fig. 14: Probability Recurrence Cumulative Distribution Function of Channel Availability for Floors 1, 2, 3 with Threshold of $+4 \mathrm{~dB}+$ noise floor [11].

Later, the Probability Cumulative Distribution Function of joint channels vs. available continuous channels was generated, with threshold of $+4 \mathrm{~dB}+$ noise floor, averaging the free channels on a daily basis as shown, which is the recommended threshold for RTL according to the ITU; this can be visualized in Figure 15 [12].

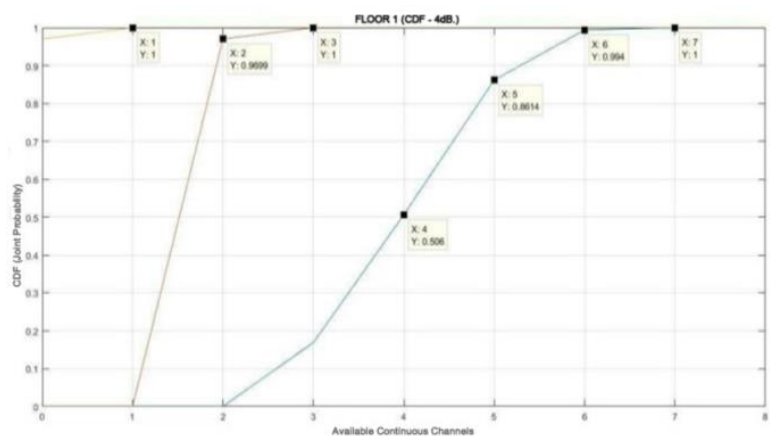

Fig. 15: Probability Cumulative Distribution Function of Joint Channels vs. Available Continuous Channels with Thresholds $+10 \mathrm{~dB}+$ noise floor and +4 $\mathrm{dB}+$ noise floor [12]

Subsequently, we proceeded to obtain the CDF Availability Density Graphics of $\mathrm{n}$ Continuous Channels for the three Floors (Floor 1, Floor 2, Floor 3), where for each floor the graphs for the thresholds of $+4 \mathrm{db}+$ noise floor and + $10 \mathrm{~dB}+$ floor noise were made. In addition, for each threshold the graphs were made taking into account a total of 7 days for each floor, and also for a total of 21 days for each floor. Next we have the graph: CDF - Availability Density of $n$ contiguous channels for FLOOR 1 considering a threshold of $+4 \mathrm{~dB}+$ noise floor, for the 7 and 21 reference days, as can be seen in Figure 16.

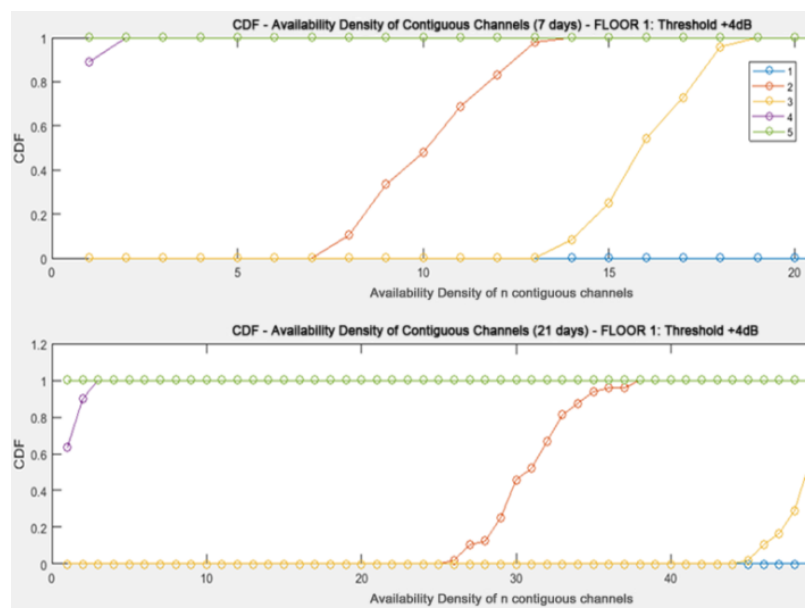

Fig. 16: CDF - Availability Density Graph of $\mathrm{n}$ contiguous channels for FLOOR 1 considering a threshold of $+4 \mathrm{~dB}+$ noise floor, for the 7 and 21 reference days.

Then we proceeded to obtain the graphs of: CDF Availability Density of $n$ contiguous channels for FLOOR 1 considering a threshold of $+10 \mathrm{~dB}+$ noise floor, for the 7 and 21 reference days, as can be seen in Figure 17.

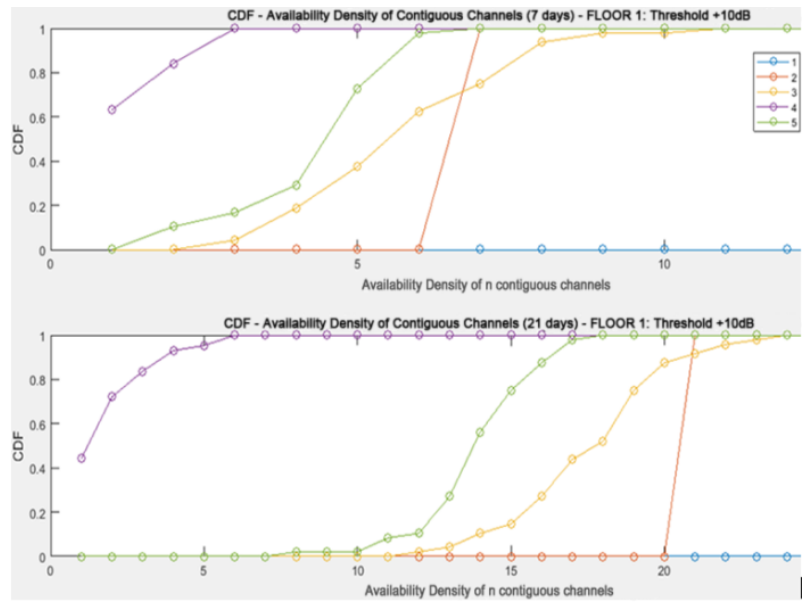

Fig. 17: CDF - Availability Density Graph of $\mathrm{n}$ contiguous channels for FLOOR 1 considering a threshold of $+10 \mathrm{~dB}+$ noise floor, for the 7 and 21 reference days.

Moving on to FLOOR 2, we obtained the graphs of: CDF Availability Density of $\mathrm{n}$ contiguous channels considering a threshold of $+4 \mathrm{~dB}+$ noise floor, for the 7 and 21 reference days, this can be seen in Figure 18. 


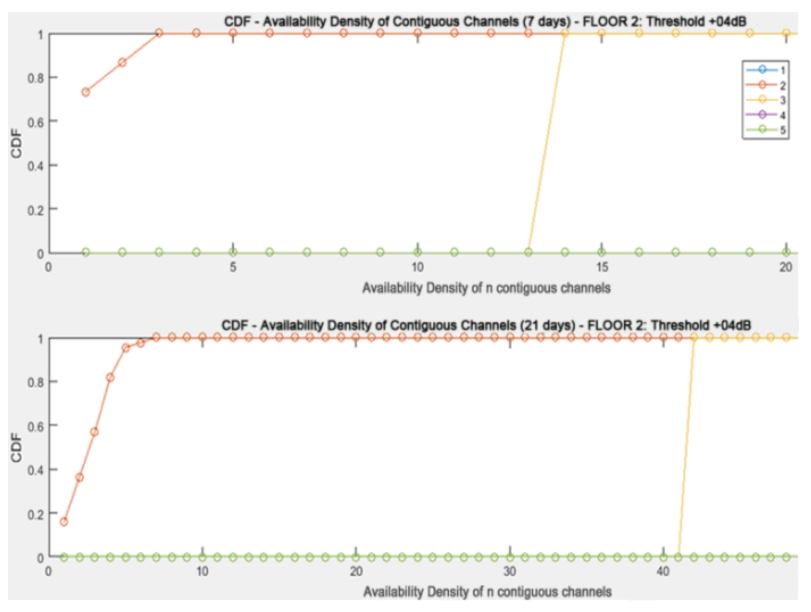

Fig. 18: CDF - Availability Density Graph of $\mathrm{n}$ contiguous channels for FLOOR 2 considering a threshold of $+4 \mathrm{~dB}+$ noise floor, for the 7 and 21 reference days.

Continuing in FLOOR 2, similarly the graphs of: CDF Availability Density of $\mathrm{n}$ contiguous channels were obtained, but considering a threshold of $+10 \mathrm{~dB}+$ noise floor, for the 7 and 21 reference days, it is observed below in the Figure 19.

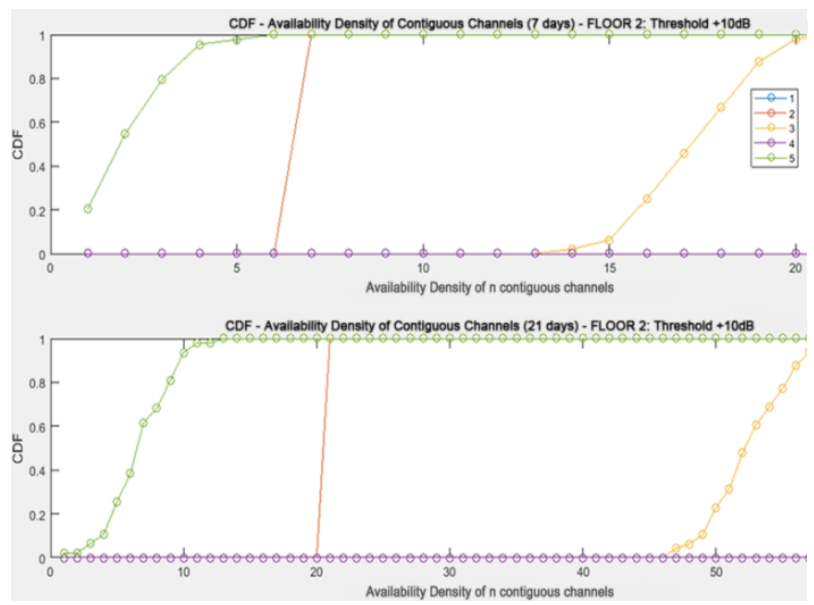

Fig. 19: CDF - Availability Density Graph of $\mathrm{n}$ contiguous channels for FLOOR 2 considering a threshold of $+10 \mathrm{~dB}+$ noise floor, for the 7 and 21 reference days.

Making the analysis for the last FLOOR 3, the graphs of: CDF - Availability Density of $n$ contiguous channels were acquired considering a threshold of $+4 \mathrm{~dB}+$ noise floor, for the 7 and 21 reference days, as can be seen in Figure 20.

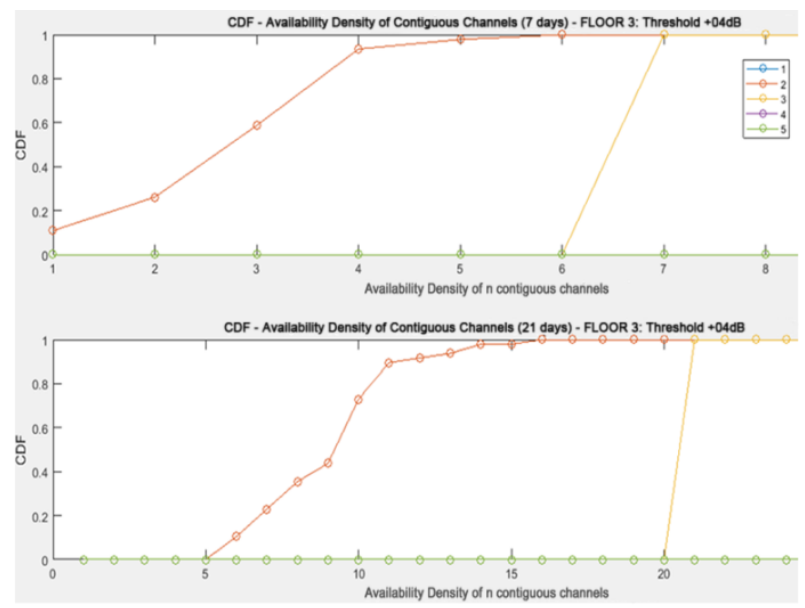

Fig. 20: CDF - Availability Density Graph of $\mathrm{n}$ contiguous channels for FLOOR 3 considering a threshold of $+4 \mathrm{~dB}+$ noise floor, for the 7 and 21 reference days.

Finally also for Floor 3, we proceeded to find the graphs of: CDF - Availability Density of $n$ contiguous channels considering now a threshold of $+10 \mathrm{~dB}+$ noise floor, for the 7 and 21 days of reference, observe the graph in the Figure 21.

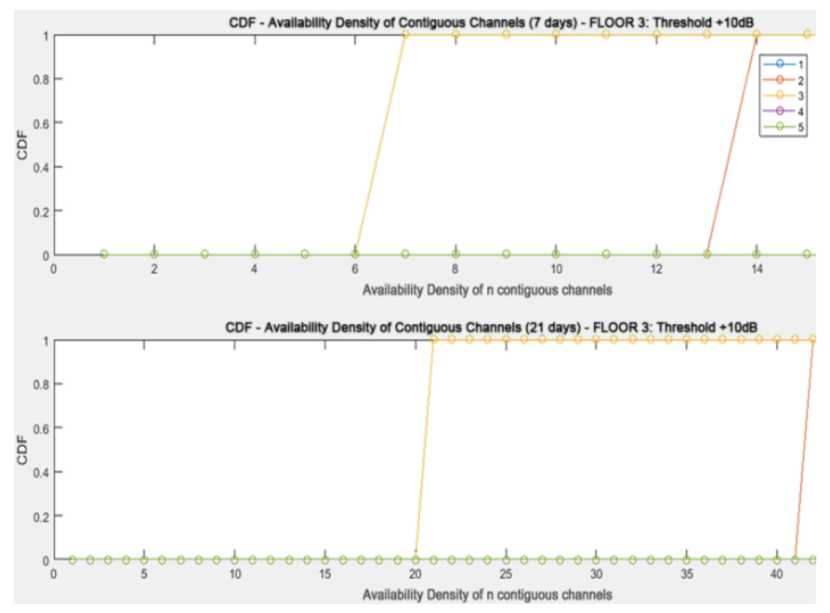

Fig. 21: CDF - Availability Density Graph of $\mathrm{n}$ contiguous channels for FLOOR 3 considering a threshold of $+10 \mathrm{~dB}+$ noise floor, for the 7 and 21 reference days.

\section{CONCLUSIONS}

Determination of technological systems based on OSA that can reuse joint channels inside a building.

Doing a probability analysis of the CDF chart - Availability Density of $\mathrm{n}$ contiguous channels for FLOOR 1 with thresholds of $+4 \mathrm{~dB}+$ noise floor and $+10 \mathrm{~dB}+$ noise floor, with 7 days of analysis we can interpret that with the Threshold of $+04 \mathrm{~dB}$ we have a $70 \%$ probability of being able to find up to 17 groups of 3 joint channels, instead with a Threshold of $+10 \mathrm{~dB}$, we have a $70 \%$ probability of being able to find up to a maximum of 6 groups of 3 joint channels. Which shows us that with the Threshold of $+04 \mathrm{~dB}$ we can

$16^{\text {th }}$ LACCEI International Multi-Conference for Engineering, Education, and Technology: "Innovation in Education and 
obtain more groupings of 3 joint channels, for which we have more spectrum available to be able to reuse it with some new technology that can be implemented in that spectrum, that is to say that the Threshold of $+04 \mathrm{~dB}$ it is the most optimal between the two thresholds.

Then, doing analysis of the same graph for FLOOR 2 for thresholds of $+4 \mathrm{~dB}+$ noise floor and $+10 \mathrm{~dB}+$ noise floor, with 7 days of analysis we can interpret that with the Threshold of $+04 \mathrm{~dB}$ we have a $70 \%$ probability of being able find up to 13 groups of 3 joint channels, instead with a Threshold of $+10 \mathrm{~dB}$, we have a $70 \%$ probability of being able to find up to a maximum of 18 groups of 3 joint channels. Which shows that in this case with the Threshold of $+10 \mathrm{~dB}$ we can obtain more groupings of 3 joint channels, for which we have more spectrum available to be able to reuse, that is to say that in this case the Threshold of $+10 \mathrm{~dB}$ is the most optimal among the two thresholds.

Then doing analysis of the same graph now for FLOOR 3 for thresholds of $+4 \mathrm{~dB}+$ noise floor and $+10 \mathrm{~dB}+$ noise floor, with 7 days of analysis we can interpret that with the Threshold of $+04 \mathrm{~dB}$ we have a $70 \%$ probability of can find up to 7 groupings of 3 joint channels, instead with a Threshold of $+10 \mathrm{~dB}$, we have a $70 \%$ probability of being able to find up to a maximum of 6 groupings of 3 joint channels. Which shows us that in this case with the Threshold of $+04 \mathrm{~dB}$ we can obtain more groupings of 3 joint channels, for which we have more spectrum available to be able to reuse, that is to say that in this case the Threshold of $+04 \mathrm{~dB}$ is the most optimal among the two thresholds.

Finally, if we make a comparison between the three floors of analysis (FLOOR 1, FLOOR 2, FLOOR 3) taking as reference the graph CDF - Availability Density of $n$ contiguous channels that we analyzed previously for measurements of 7 days and a Threshold of $+04 \mathrm{~dB}$, we can conclude that FLOOR 1 is the floor that more groupings of three joint channels can be reached between them, with a $70 \%$ probability of being able to find up to 17 groups of 3 joint channels, instead the FLOOR 3 is the floor that fewer groupings of three joint channels can be obtained among them, with a $70 \%$ probability of being able to find up to only 7 groupings of 3 joint channels.

The total amount of available spectrum of joint channels that is observed in the obtained results, can be reused with the implementation of new types of wireless devices with cellular radio technologies (LTE or HPSA +), that can use the available temporal or spatial spectrum.

Through the spectral measurement of the UHF-TV band, on day 12 was possible to identify that there were, on average, 5 free channels ready to be reused, with an equivalence of 30 $\mathrm{MHz}$ in total - all of this with an $11.36 \%$ probability of occurrence.

Considerable battery savings in wireless devices can be achieved if they know the number of optimal radio channels with the OSA methodology.

It was possible to highlight the availability of some individual channels for certain hours: at 00:00, 15:00 and
20:00 in the High Floor - 28.57\% of availability for channels 1 and 30; at 3:30 and 21:30 in the Middle Floor - 76.19\% of availability for channels $5,12,20,21$ and 29 ; and at 17:30 on the Ground Floor - 90\% of availability for channel 3; all of these results were analyzed for the period of 21 days.

The analysis of the spatial and temporal effect on the number of available channels within the study building, has allowed us to describe the effect of the underutilization and poor spectrum efficiency.

\section{ACKNOWLEDGMENT}

Escuela Superior Politécnica del Litoral - FIEC. ING. WASHINGTON MEDINA, M.SC.

\section{REFERENCES}

[1] Novillo, F.; Gomez, J.; Medina, W., "Channel Availability Characterization in TV bands for OSA Devices Inside Buildings," IEEE Latin America Transactions, vol. 14, no. 6, Jun. 2016

[2] Wang, B.; Ray Liu, K. J., " Advances in cognitive radio networks: A survey,"IEEE Journal of Selected Topics in Signal Processing, vol. 5, no. 1, Feb. 2011

[3] Federal Communications Committee, Mobile Broadband: The benefits of additional spectrum. Technical Report, Federal Communications Committee (FCC), 2010

[4] Shimomura, T.; Oyama, T.; Seki, H., "Analysis of TV White Space Availability in Japan," Vehicular Technology Conference (VTC Fall), 2012 IEEE , vol., no., pp.1,5, 3-6 Sept. 2012

[5] van de Beek, J.; Riihijarvi, J.; Achtzehn, A.; Mahonen, P., "TV White Space in Europe," Mobile Computing, IEEE Transactions on, vol.11, no.2, pp.178,188, $\quad$ Feb. 2012 [6] Novillo, F.; Galeana, H.; Ferrus, R.; Agusti, R., "Spectrum Availability in Indoor Locations for Opportunistic Spectrum Access in Dense Urban Scenarios," Vehicular Technology Conference, 2009. VTC Spring 2009. IEEE 69th, vol.,no., pp.1, 5, 26-29, April 2009

[7] Novillo, F.; Ferrus, R., "Channel Assignment Algorithms for OSAEnabled WLANs Exploiting Prioritization and Spectrum Heterogeneity," IEICE Transactions on Communications, vol. e95-b, no. 4, pp.1125-1134, April 2012

[8] Petri Mähönen and Janne Riihijärvi, Chapter 9 - Cognitive radio network architectures, In Cognitive Radio Communications and Networks, edited by Alexander M. WyglinskiMaziar NekoveeY. Thomas Hou, Academic Press, Oxford, 2010, Pages 235-260, ISBN 9780123747150, http://dx.doi.org/10.1016/B978-0-12-374715-0.00009-5.

[9] Yanpeng Yang; Lei Shi; Zander, J., "On the capacity of Wi-Fi System in TV white space with aggregate interference constraint," Cognitive Radio Oriented Wireless Networks (CROWNCOM), 2013 8th International Conference on , vol., no., pp.123,128, 8-10 July 2013.

[10] Ying, X.; Zhang, J.; Yan, L.; Zhang, G. ; Chen, M. ; Chandra R., "Exploring Indoor White Spaces in Metropolises," MobiCom'13, ,Sept 30Oct-4 Miami, FL,USA.

[11] R. Urgaonkar y M. Neely, "Opportunistic scheduling with reliability guarantees in cognitive radio networks", in Proc. IEEE International Conference on Computer Communications (INFOCOM), 2008, pp. 13011309.

[12] R. Etkin, A. Parekh, and D. Tse, "Spectrum sharing for unlicensed bands," in

Proc. 1st IEEE Symp. New Frontiers Dynamic Spectrum Access Networks, 2005,

pp. 251-258.

[13] BERLEMANN, Lars; DIMITRAKOPOULOS, George; MOESSNER. Klaus; HOFFMEYER, Jim; "COGNITIVE RADIO AND MANAGEMENT OF SPECTRUM AND RADIO RESOURCES IN RECONFIGURABLE NETWORKS" Wireless Word research Forum, Working Group 6 (WG6). White paper.

$16^{\text {th }}$ LACCEI International Multi-Conference for Engineering, Education, and Technology: "Innovation in Education and Inclusion", 19-21 July 2018, Lima, Peru. 
[14] REGLAMENTO GENERAL DE LA LEY DE TELECOMUNICACIONES REFORMADA Registro Oficial No. 404 del 4 de septiembre de 2001

[15] LIANG, Y.-C., K.-C. CHEN, G. Y. LI AND P. MÄHÖNEN Cognitive Radio: Networking and Communications An Overview. IEEE Trans. Veh. Technol., 2011, 60(7), 3386 - 3407.

[16] Comission for Comunications Regulation (ComReg). "DYNAMIC SPECTRUM ACCESS- Briefing Note". Document No 07/22 13 Abril 2007.

[17] Q. Zhao, "Spectrum opportunity and interference constraint in opportunistic

spectrum access," in Proc. IEEE Int. Conf. Acoustics, Speech, Signal Processing

(ICASSP), April 2007.

[18] MITOLA, Joseph III; MAGUIRE, Gerald Jr.; "COGNITIVE RADIO: MAKING SOFTWARE RADIOS MORE PERSONAL". IEEE Personal Communications, Agosto 1999

[19] HAYKIN, Simon; "COGNITIVE RADIO BRIAN-EMPOWERED WIRELESS COMUNICATIONS" IEEE Journal on Selected Areas in Communications February 2005.

[20] P. Pawelczak y otros, "State of the art in opportunistic spectrum access medium access control design", in Proc. IEEE International Conference on Cognitive Radio Oriented Wireless Networks and Communications (CrownCom), mayo 2008, pp. 1-6.

[21] CHOWDHURY, K. R. AND I. F. AKYILDIZ Cognitive Wireless Mesh Networks with Dynamic Spectrum Access. IEEE J. Sel. Areas Commun., January 2008, 26(1), 168181 .

[22] Agencia de Regulación y Control de las Telecomunicaciones Ecuador. Plan Nacional de Frecuencias Ecuador 2012, 2012.

[23] Realizing the Full Potential of Government-held Spectrum to Spur Economic Growth, Jul 2012, President's Council of Advisors on Science and Technology.

[24] J. Pierre De Vries, Ljiljana Simic, Andreas Achtzehn, Marina Petrova, and Petri Mahonen. The emperor has no problem: Is Wi-Fi spectrum really congested? In TPRC 41: The 41st Research Conference on Communication, Information and Internet Policy, March 2013.

[25] Ericsson Mobility Report, June 2015, ERICSSON.

[26] Medina, W.; Gomez, J.; Novillo, F.; Romero, J.,"Availability of adjacent TV channels inside buildings of dense urban scenarios for use of short-range devices with OSA capabilities," Communications (LATINCOM), 2016 8th IEEE Latin-American Conference on, vol., no., pp., 15-17 Nov. 2016.

[27] Hossain, E.; Niyato, D. \& Han, Z. Dynamic Spectrum Access and Management in Cognitive Radio Networks, Cambridge University Press, 2009.

[28] Qing Zhao; Sadler, B.M., "A Survey of Dynamic Spectrum Access," Signal Processing Magazine, IEEE, vol.24, no.3, pp.79, 89, May 2007

[29] I. F. Akyldiz, W-Y Lee, M C. Vuran, S Mohanty, "NeXt generation/dynamic spectrum access/cognitive radio Wireless networks: A Survey", Elsevier, 2006.

[30] Guía de Prácticas de Laboratorio de Telecomunicaciones ESPOL Practica 8.

$16^{\text {th }}$ LACCEI International Multi-Conference for Engineering, Education, and Technology: "Innovation in Education and Inclusion", 19-21 July 2018, Lima, Peru. 